it could draw together such participants and many will feel that the Foundation is owed a debt of gratitude for publishing these deliberations.

M.W.

\section{THE MEDICAL ANNUAL}

Edited by Sir Henry Tidy, K.B.E., M.A., M.D., F.R.C.P., and R. Milnes Walker, M.S., F.R.C.S., with 47 contributors. Pp. xliv +548 , with 63 illustrations. Bristol: John Wright \& Sons Ltd. 1955. 32s. 6d.

This book is an annual abstract of important papers of general interest. Mohammed can no longer go to the mountain of medical literature, and this annual successfully brings a panoramic glimpse of the mountain to Mohammed. Its success is based upon expert editing and a galaxy of contributors of an eminence rarely found in abstracting services.

No doubt there are economic reasons for the unfortunate inclusion of drug-plugging advertisements, but even these include such intriguing matters as ' a culture for Candida.' Again, some hormones continue to be issued in blunderbuss combinations and, the medicinal compound of the ballad, are efficacious in every case.

The volume can be highly recommended to doctors in every branch of the profession. There can be few medical books with such a universal appeal.

I.L.E.

\section{MYSTERIOUS WATERS TO GUARD}

By Leslie Bourne, M.D., C.M., M.Sc., F.R.C.P., F.I.C.A., D.A., F.A.C.A., F.F.A.R.C.S. Pp. xvi + 398, illustrated. Oxford: Blackwell Scientific Publications. 1955. 42S.

Under this title is published a collection of addresses and essays by the distinguished Canadian Anaesthetist, Dr. Leslie Bourne, Emeritus Professor of Anaesthesia at McGill University, during the last 30 years.

Dr. Bourne deals with a wide variety of subjects in his addresses. There are two short historical reviews; accounts of recent advances given in the years 1934, 1948 and 1950; the choice of anaesthesia for tuberculous patients and for emergency surgery; and many other subjects. His style is clear and easily readable, but his tendency to commence his addresses with references to the great philosophers and the occasional inclusion of poetry seems pompous.

Among his essays are his impressions of the celebrations of the Centenary of Anaesthesia in London in 1946, which was printed in Anaesthesiology in 1948, and an essay entitled 'Breathing in Anesthesia' which appeared as an editorial in the same journal in March 1942.

A criticism of the work is the inclusion of many chapters with much the same content. Subjects discussed with much frequency in the first half of the book are Metabolic Changes in Anaesthesia; Analgesia in Obstetrics; Analeptics; and Premedication for Relief of Pre-operative Fear, while descriptions of the three-year course in Anaesthesia at McGill University occur in at least three chapters in the latter half.

Photographs of many well-known anaesthetists and scientists from various parts of the world and professors at McGill University, and inexplicably of a late headmaster of the Lodge School, Barbados, are distributed through the book.

Full references are given at the end.

The printers have erred badly in the top line of page 146 , otherwise the book is well produced.

\section{BREAST CANCER AND ITS DIAGNOSIS AND TREATMENT}

By Edward F. Lewinson, B.S., M.D., F.A.C.S. Pp. 478. London: Baillière, Tindall and Cox. 1955. I 14 s.

This book is a comprehensive presentation of modern thought and knowledge regarding carcinoma of the breast. Every conceivable aspect of the subject is fully dealt with, the British and American literature is thoroughly reviewed; the illustrations are of high standard and, for the most part, the text is clear and logical.

As might perhaps be expected from a member of the surgical school founded by Halsted, the author is a staunch supporter of radical mastectomy. He appears to look to extended radical mastectomy forco future advances in treatment and has little use for the? conservative attitude towards operation which has become popular in recent years. It cannot be said that he produces convincing proof to support these views.

H.L.B.

\section{CORNEAL GRAFTS}

Edited by B. W. Rycroft, O.B.E., M.D., D.O.M.S., F.R.C.S. Pp. xii +285 . London: Butterworth \& Co. Ltd. I955. 57s. 6d.

This, the first text book on Corneal Grafting to be published in English, is a welcome and important addition to ophthalmic literature. The list of I 5 contributors from five countries (Britain, France, Spain, Switzerland and the United States) is an impressive one. It includes many of the leading authorities on the subject throughout the world. The result is a reliable and well-balanced account of every aspect of keratoplasty.

The first three chapters deal with the history of the operation, the anatomy and physiology of the cornea and the histo-pathology of corneal grafts. Apart from providing a useful introduction to the clinical side of the subject, they should be of value to everyone interested in tissue grafting. The main body of the book is devoted to the selection of cases, the operative details of lamellar and perforating 